\title{
Drilling-and-blasting method of demolition
}

\author{
Denis Sinitsyn ${ }^{1, *}$ \\ ${ }^{1}$ Moscow State University of Civil Engineering, 26, Yaroslavskoe Shosse, Moscow, Russia
}

\begin{abstract}
This article analyzes the experience and gives the examples of dismantling and demolition of the construction structures of the buildings and facilities using the drilling-and-blasting method. The drilling-andblasting method is widely used in construction and reconstruction. The demolition means may be classified according to impact on a material of structures to be demolished and to forces application, where, by virtue of an impact energy type, we choose the blasting method. This method is used during the complete demolition or fragmentation of concrete, reinforced concrete, masonry structures, of old buildings and facilities demolition to their base or in the intended direction. Blasting method may be used as well during the steel and reinforced concrete structures demolition to the smaller easy-to-move parts. Reviewed are the organizational-process activities, which are performed during the various structures dismantling. Given are the areas of application for the various methods of structures demolition. Given is the example of demolition of "Severnaya" boiler house brick chimney at the territory of Murmansk DSK using the blast in confined spaces of the operating company. Subject of research: methods of construction structures demolition in alarm situations and acts of God. Objects: determination of the most efficient demolition methods in the present conditions of construction operations development. Materials and methods: the developed activities on the construction structures dismantling are given. Results: the most efficient methods and ways of construction structures demolition are defined. Conclusions: it is required for improvement of methods and ways of the structures drilling-andblasting demolition.
\end{abstract}

\section{Introduction}

The drilling-and-blasting method of the construction structures demolition is widely used during the construction and reconstruction of buildings and facilities in specific [1-10].

This method is based on use of the blast energy, which occurs under the influence of spark or impact initial impulse to blasting material.

\footnotetext{
* Corresponding author: sasin50@mail.ru
} 
Table 1. The method of disassembly of a monolithic structure.

\begin{tabular}{|c|c|c|}
\hline $\begin{array}{l}\text { Type of } \\
\text { monolithic } \\
\text { structure }\end{array}$ & Dismantling method & $\begin{array}{c}\text { Work labour input, } \\
\text { pers-hr for } \\
\text { dismantling of } 1 \mathrm{~m} 3\end{array}$ \\
\hline \multirow{4}{*}{$\begin{array}{l}\text { Mass } \\
\text { concrete }\end{array}$} & Manually (depending on a concrete grade) & $58-84$ \\
\hline & By applying of pneumatic tool (depending on a concrete grade) & $29-42$ \\
\hline & Drilling-and-blasting method & 5,6 \\
\hline & By applying of electrohydraulic effect plant & 0,37 \\
\hline \multirow{4}{*}{$\begin{array}{l}\text { Mass } \\
\text { rubble } \\
\text { concrete }\end{array}$} & Manually (depending on the solution grade and composition) & $3,7-5,7$ \\
\hline & $\begin{array}{l}\text { By applying of pneumatic tool (depending on the solution grade } \\
\text { and composition) }\end{array}$ & $2,4-3,5$ \\
\hline & Drilling-and-blasting method & 3,1 \\
\hline & By applying of electrohydraulic effect plant & 0,33 \\
\hline \multirow{4}{*}{$\begin{array}{l}\text { Brick } \\
\text { laying }\end{array}$} & Manually (depending on the solution grade and composition) & $3,1-5.5$ \\
\hline & $\begin{array}{l}\text { By applying of pneumatic tool (depending on the solution grade } \\
\text { and composition) }\end{array}$ & \\
\hline & Drilling-and-blasting method & 3,0 \\
\hline & By applying of electrohydraulic effect plant & 0,32 \\
\hline
\end{tabular}

This method is long-applied in construction operations; it is reviewed sufficiently in the technical literature. So it does not seem necessary to enlarge upon this method. Focus on the example of the brick chimney demolition (with internal diameter of $6 \mathrm{~m}$ and with height of $72 \mathrm{~m}$ ) of "Severnaya" boiler room located at the territory of Murmansk integrated homebuilding factory using the blast in tight working space of the operating company [9]. This chimney was located within $3 \mathrm{~m}$ from the existing boiler room, within 1,5 m from the crane trestle supports of unsheltered warehouse for the sand and spalls storage, and within $10 \mathrm{~m}$ from a new-built chimney (Fig. 1.).

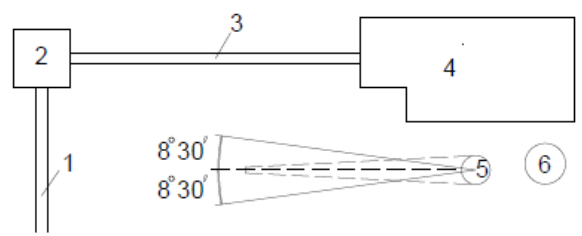

Fig. 1. Layout plan of the facilities, and the chimney fall diagram on its demolition by the drillingand-blasting method. Where: 1,3 -passageways; 2 - intermediate bunker; 4 - boiler house; 5 chimney to be demolished; 6 - new-built chimney.

The difficulty of works execution was in that the chimney was meant to fall in strictly specified direction, with the maximum deviation for no more than $8^{\circ} 30^{\prime}$. At the same time, by comparison of the possible variants of the chimney dismantling, it turned out that the drilling-and-blasting method was the cheapest and less labourious; so, notwithstanding the tight working space of the site, the decision was taken to use this method.

\section{Methods}

To execute the works, in the chimney body made were 36 blast holes, with their depth equal to $2 / 3$ of the brick laying thickness. For their drilling applied were the drilling 
machines PR-ZOL equipped with the crown drills in diameter $36 \mathrm{~mm}$. The latter ones were set with hard alloy VK-15. The drill hammers were connected to the compressor DK-9 by applying of drill hammers. The works were executed by the team consisting of two persons. They made and charged blasting holes with blasting material. The blasting holes had a conical form in their section, tapering to the center of proposed axis location of the fallen chimney. These blast holes were arranged in four series and checkerwise. The detonite was applied as the blasting material [10]. It was blasted by applying of instantaneous electric detonators ED-8-ZPS. To protect the existing facilities from the brick laying shatters during the blast, the lower part of chimney was covered with heavy wooden shields to the height of blast holes installation. The correct calculation and the accurate works execution have allowed demolishing the chimney strictly in the specified direction. The duration of works was equal to $10 \mathrm{hr}$.

During the reconstruction of workshops of a winery in Armenia, it was required to dismantle a reinforced concrete tankage, which was used for wine storage. This tankage was made as the rectangular facility, consisting of 20 tanks. The square tanks with sides dimensions of $2,8 \mathrm{~m}$ each, and with height of $1,8 \mathrm{~m}$, were arranged in two series. The distance between them was equal to $1,5 \mathrm{~m}$. The thickness of walls, deck and head was the same for each tank $-0,25 \mathrm{~m}$. the rolled sections (U-bars, I-girders, etc.) and reinforcement bars were used for reinforcement. The tankage was located at the distance of $10-20 \mathrm{~m}$ from the operating workshops. The glass wine line consisting of three strings was run at the distance of 10 from tanks, on both sides of these ones.

\section{Results}

The application of breaker hammers and excavator equipped with demolition ball, for dismantling of the tankage specified was ineffective in view of reinforced concrete high strength. It was suggested to apply for the blast method $[10,11,12,13,14]$. Considering that the works were executed under the conditions of operating company and nearby the existing utilities and facilities, it was decided to use the hydro-blasting method. In this regard, the tanks were filled with water up to the brim, all hatches were tightly closed. The holes with dimensions of $10 \mathrm{X} 10 \mathrm{~cm}$ were drilled in the decks of tanks; the blasting material charges were run through these holes. Fig.2.

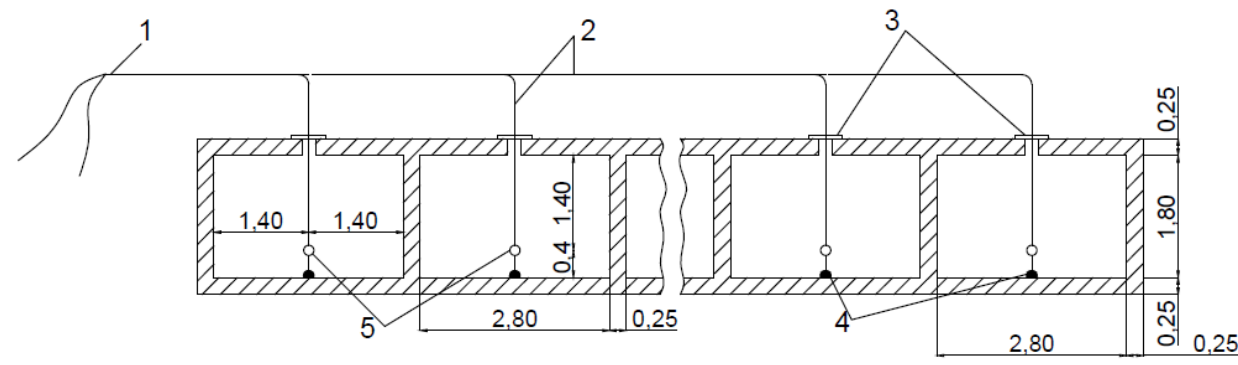

Fig. 2. Diagram of hydro-blasting works execution during the dismantling of reinforced concrete tankage. 1 - electric detonator; 2 - detonating cord; 3 - fixing lugs for detonating cord hanger; 4 block; 5 - blasting material charge.

The value of mass of charges was calculated using the formula:

$$
\varrho=2,6 c^{2}\left[\sigma_{c k}+(h i a) \delta_{p}\right]^{2}: 10
$$


where $\mathrm{c}$ - tank walls thickness $(0,25 \mathrm{~m})$;

$\sigma_{c k}$ - ultimate shearing resistance of reinforced concrete $(950000 \mathrm{~N} / \mathrm{cm} 2)$;

$\delta_{p}$ - ultimate tensile strength of reinforced concrete $(240000 \mathrm{~N} / \mathrm{cm} 2)$;

$\mathrm{h}$ - height of band to be blasted $(1,4 \mathrm{~m})$;

a - distance between working reinforcement $(0,4 \mathrm{~m})$;

$\mathrm{i}$ - charge depth $(1,4 \mathrm{~m})$;

$\mathrm{R}$ - distance from the tank center to the wall, $\mathrm{m}$.

According to the foregoing formula determined was the mass of charge per one tank, which was equal to $0,7 \mathrm{~kg}$.

The water-resistant ammonite NoB JV was used as the blasting material. The charge of ammonite was put into a cellophane bag, as well as the detonating cord. The whole detonating system was assembled from the latter one. The injection was executed by applying of instantaneous electric detonators, which were connected to the end sections of the detonating cord main lines. The machine KPM-1 was used as the current source.

The blast was executed without the concrete fragments distribution. Herewith, the maximum value of the latter ones in diameter was no more than $0,7 \mathrm{~m}$. To execute the works used were $14 \mathrm{~kg}$ of ammonite, $170 \mathrm{~m}$ of detonating cord, 4 electric detonators, 20 cellophane bags. As is seen from the given examples, the blasting method of structures demolition is the most efficient and the cheapest in certain circumstances.

The procedure of works execution concerning the buildings dismantling contains a variety of process operations. The building shall be dismantled element-by-element; it provides for the works safety and reduces the time limits of their execution. The dismantling procedure, the methods of elements slinging operations, securing strap of structures, etc., are specified by PPR.

All foregoing methods of works execution may be used for the buildings dismantling. Herewith, in most cases, used is the combined method, where some structural components are dismantled, for example, by mechanical method, others - by drilling-and-blasting method, still others - manually, etc. Besides, it is possible to use only the drilling-andblasting method. Consider the following specific examples.

During the reconstruction of one of the workshops of Kirovsky Zavod, St. Petersburg, it was required to dismantle a part of the workshop (the premise of fettling room) due to addition of new bay with dimensions of $30 \mathrm{~m}$. The dimensions of the area to be dismantled were equal to $18 \mathrm{X} 48 \mathrm{~m}$. In the central bay of this area located was the lantern. The roof was lean-to, with the least reduced level (from the finished floor level) equal to $7,56 \mathrm{~m}$ along the axis 16 .

Prior to dismantling works execution, the workshop area was free from the process equipment, blanks and end products, as well as shut off were all utilities (water supply and sewage, vapor, air, gas, etc.). The shutting off of the workshop area to be dismantled from the utilities was documented by the appropriate act, following which the subcontracting company obtained the certificate of unavailability of the exiting utilities in the area of proposed works, as well as the written permit for dismantling of this part of the building.

The works were executed in two stages. The diagram of first-stage disassembly is given in Fig. 3. 


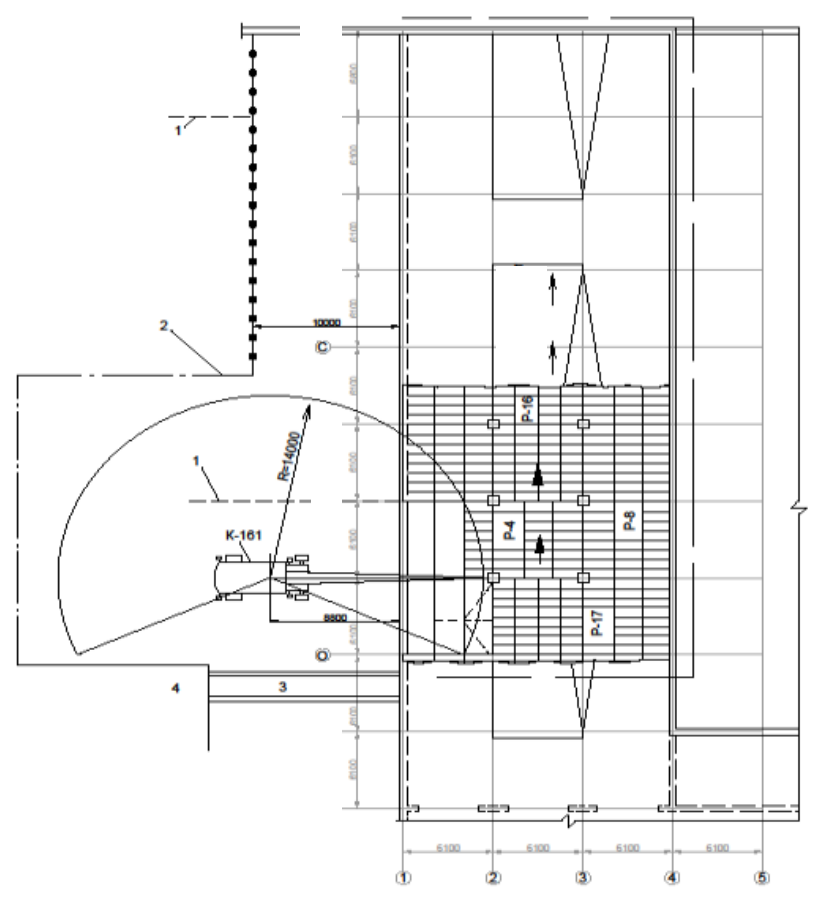

Fig. 3. Diagram of disassembly of the roof elements during the dismantling of the premise of fettling room (1st stage of works). $P-4, P-8, P-16$ and $P-17$ - identification mark of roof slabs - designed bay; 2 - demountable fence; 3 - existing passage way; 4 - accommodation building.

Herewith, the following procedure of works execution was used.

At first stage dismantled was the roof area at a width of one column step. Then dismantled was the brick wall, by applying of breaker hammers from the metal scaffolds. Following that, dismantled were the roof areas, as well as columns, resulting in installation of crane inside the dismantled part of the building.

At the second stage of dismantling, the works were executed in the direction of axis 3 . At first, disassembled were covering elements of the lantern, and then the works were executed at the adjoining areas. The lantern trusses were fastened as illustrated in Figure. The crane runway beams and columns were dismantled in the last turn. The remaining part of the wall was dismantled after the windows.

\section{Conclusions}

The aforesaid methods are widely used in the construction operations. They are sufficiently effective during the demolition of construction structures of buildings and facilities.

\section{References}

1. G.V. Tchernova, N.A. Kudryavstev, Risk management (M TK Velbi, 2005)

2. V.A. Zarenkov, Project management (M St. Petersburg ACB, 2006)

3. P.G. Graboviy, Yu.N. Kulakov, Economy and property management (M ACB, 1999)

4. P.P. Oleynik, Construction organization, conceptual frameworks, models and methods, information-utility systems (M Profizdat, 2001) 
5. B.V. Zhadanovskiy, Industrial and civil construction, 4 (2017)

6. B.F. Shirshikov, S.A. Sinenko, B.V. Zhadanovskiy, M.F. Kuzhin, V.I. Brodskiy, MGSU (2015)

7. M.S. Vainshtein, B.V. Zhadanovskiy, S.A. Sinenko, A.A. Afanas'yev, Science review 13, 123-127 (2015)

8. T.V. Zolina, Application for assessment methods of operation life of industrial building with cranage throughout its life cycle (AISI, Astrakhan, 2014)

9. T.V. Zolina, Vestnik MGSU 14, 98-108 (2014)

10. S.F. Prokhorkin, Construction and installation works technology and organization during the industrial enterprises reconstruction (Stroyizdat, 1976)

11. B.F. Shirshikov, S.A. Sinenko, A.M. Slavin, B.V. Zhadanovskiy, M.F. Kuzhin, V.I. Brodskiy, Organizational-process solutions on the labour safety in the work execution designs (Moscow, 2015)

12. M.S. Vainshtein, B.V. Zhadanovskiy, S.A. Sinenko, A.A. Afanas'yev, A.S. Pavlov, A.Z. Efimenko, A.I. Dolganov, Science review 13, 123-127 (2015)

13. S.A. Sinenko, M.F. Kuzhin, B.F. Shirshikov, B.V. Zhadanovskiy, V.I. Brodskiy, Yu.A. Shesterikov, V.F. Smokin, Projects development of organization of industrial buildings and facilities construction (Moscow, 2016)

14. B.V. Zhadanovskiy, S.A. Sinenko, Science review 7, 39-43 (2016)

15. T.K. Kuz'mina, S.A. Sinenko, Science review 7, 222-227 (2016) 